\title{
Characteristics of the association between the marine copepod, Gastrodelphys clausit, and its fanworm host Bispira volutacornis
}

Received: 27 August 2003 / Revised: 26 July 2005/ Accepted: 19 August 2005/Published online: 8 October 2005

(C) Springer-Verlag and AWI 2005

\begin{abstract}
Characteristics of the association of the marine copepod Gastrodelphys clausii with its fanworm host Bispira volutacornis were investigated from October 1997 to August 1999. Of the 982 hosts examined, $22.6 \%$ were infected, with male copepods outnumbering females. Prevalence varied between 3 and $90 \%$ during the study period and showed a seasonal pattern with a summer and late autumn/winter peak. Hosts were observed to harbour both single and multiple infections. The aggregation of parasites within the host population was overdispersed, displaying a characteristically clumped pattern. G. clausii reaches adulthood in males at ca. $800 \mu \mathrm{m}$ in length, with recorded total lengths extending to $1,875 \mu \mathrm{m}$. Females at maturity were recorded to be ca. $1,000 \mu \mathrm{m}$, with a maximum total length of $3,250 \mu \mathrm{m}$ recorded for an ovigerous female. Copepods were mobile within the branchial crown and showed no statistical preference for branchial crowns of different sizes. A positional pattern, however, was observed with juvenile copepods observed to occupy radioles further from the prostomium, as the branchial crown increases the number of radioles in each spiral. Contrary to this, the majority of female copepods were located attached to the radioles closest to the prostomium irrespective of crown size.
\end{abstract}

Keywords Copepod $\cdot$ Sabellid $\cdot$ Parasite $\cdot$ Host

\section{Introduction}

Bispira volutacornis (Montagu) is host to the copepod Gastrodelphys clausii Graeffe, a member of the order

Communicated by K. T. Jensen

Brendan F. Keegan: deceased author

R. Nash $(\varangle) \cdot$ B. F. Keegan

Martin Ryan Institute, National University of Ireland, Galway,

Ireland

E-mail: roisin.nash@nuigalway.ie

Tel.: + 353-91-493209

Fax: + 353-91-525005
Poecilostomatoida, which is the most diverse order of copepods in terms of body morphology. Virtually all poecilostomatoids are parasitic, or closely associated with other animals, and the majority are marine (Huys and Boxshall 1991). Members of the family Gastrodelphyidae, in which G. clausii is included, are described as symbionts of polychaetes worms of the family Sabellidae. Mature adult females seem to be associated with particular worm species, except for Gastrodelphys dalesi Green which is host specific at the generic level (Dudley 1964). The copepodid stages, adult males, and immature adult females of Sabellacheres illgi Dudley, however, exhibit some peregrination among worms of different genera and species (Dudley, loc. cit.).

The first observations of the copepod G. clausii were made by De St. Joseph (1875) on the Brittany coast. Graeffe (1883) first described the copepod from its host B. volutacornis (then known as Distylia josephina) from the Adriatic Sea. Further specimens were found in 1890 and were redescribed by List (1890). In the present study, we report the first occurrence of this copepod in Ireland. The study site was Lettercallow Bay $\left(53^{\circ} 17.4^{\prime} \mathrm{N}\right.$, $9^{\circ} 42^{\prime} \mathrm{W}$ ) within Kilkieran Bay on the west coast of Ireland. G. clausii has never been recorded other than with its host, B. volutacornis, and then from only two locations outside Lettercallow, Muggia Bay near Trieste, Adriatic Sea (Graeffe 1883) and Dinard on the Brittany coast of France (De St. Joseph 1894). Monthly samples of $B$. volutacornis were collected by SCUBA divers, between October 1997 and August 1999, to determine the incidence of $G$. clausii. Although we are convinced of the essentially symbiotic nature of the association, there also appears to be strong evidence to suggest that the lifestyle of $G$. clausii has a tendency towards parasitism.

\section{Materials and methods}

The host was relaxed using menthol crystals and the copepod removed. Menthol crystals were also used for anaesthetising G. clausii (15 $\mathrm{min}$ ) prior to transferring 
the copepods to a $70 \%$ alcohol fixative containing a drop of glycerine. A total of 982 polychaetes were examined and 327 individual copepods were recorded and measured to determine size distribution and class size frequency using FiSAT (Fao-iclarm Stock Assessment Tools, Gayanilo et al. 1995). A modal progression analysis was done on male and female size distributions, together and separately, where each mode on the size frequency histograms was interpreted as representing a single age-class. Bhattacharya's (1967) method was used to obtain initial guesses. The results were refined using NORMSEP (i.e. SEParation of the NORMally distributed populations) (Gayanilo et al. 1995). Monthly sample sizes ranged from 10 to 172 with an average sample size of 50 polychaetes.

Six infected worms, with 1-2 adult copepods, were removed from their tubes, and placed in $500 \mathrm{ml}$ of oxygenated seawater, from which all particulate matter had been removed by passing it through a Buchner funnel with a glass microfibre filter (with a $1.2 \mu \mathrm{m}$ retention). The water and glass containers were also autoclaved prior to use to kill bacteria that might constitute an alternative source of food. Polychaetes were fed with carmine solution to show when their guts had emptied (i.e. ca. $9 \mathrm{~h}$ later). At this point, the infected hosts were transferred to new containers containing similarly prepared water. Six adult copepods, isolated from their hosts, were also placed in vessels with similarly prepared water.

To differentiate between the positional patterns of male, female and juvenile copepods, it was first necessary to divide the crown of all examined specimens into two and to concentrate on one spiral as representative of the crown at large. Due to the large variation in crown dimensions, a number of size groups were created, reflecting the number of radioles in one spiral: 1, 20-40; $2,41-60 ; 3,61-80 ; 4,81-120$. The subsequent examination involved the sexing and measurement of all parasites on the host, their distance from the basal web and the 'numbered' radiole to which they were attached. Following this, each copepod was assigned to the branchial crown size group from which it had been taken. The internal diameters of the smaller hooks on the second antennae of 50 copepods were also measured. Radioles located on the dorsal edge of the first spiral are designated in the text as 'older' radioles, being the first to appear on the crown. Most recently added radioles appear at the tip of the spirals and are referred to in the text as 'younger'. Voucher specimens can be found in the Natural History Museum, London.

\section{Results}

In $G$. clausii, the deeply forked rostrum and the second antenna, bearing three hooks and a spoon-shaped process held in opposition to hooks, had previously been indicated as appendages for attachment. The inner pair of hooks was recorded to have an internal diameter of ca. $11 \mu \mathrm{m}$, slightly smaller than the diameter of the pinnules of $B$. volutacornis, which ranged from 20 to $25 \mu \mathrm{m}$. However, during this study, a number of copepods were also observed to use their post-oral plates as an aid in attachment (Fig. 1).

Gastrodelphys clausii had gut contents of a deep purple colour very similar to the pigmentation of the pinnules of its host B. volutacornis. Food particles gathered from the immediate vicinity of the duo reflected
Fig. 1 Detached fragments of pinnular epithelium attached to both the post-oral plate and to the first antenna on the female Gastrodelphys clausii. A1, first antenna; A2, second antenna; pop, post-oral plate; $p s$, pinnular epithelium

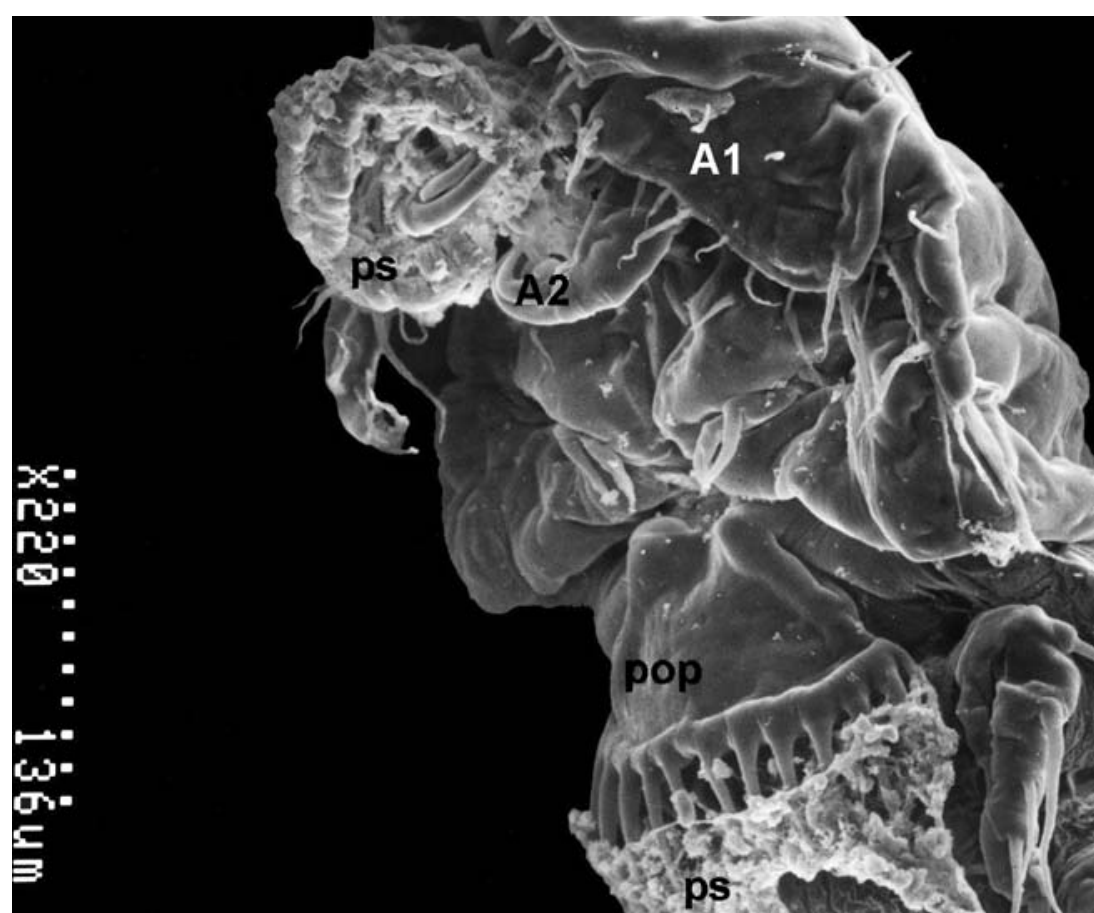


a range of colours, with no distinct particle or combination of particles seen to parallel the deep purple pigmentation of the host. The nature of the association between $G$. clausii and B. volutacornis was clarified by observing attached and unattached copepods in filtered seawater over an 11-day period. Copepods attached to their hosts survived in ambient water beyond the duration of the experiment with their host. They survived for ca. 9 days in filtered seawater, where the condition of the host deteriorated from day 8 , with only slow movements observed, while the copepods remained active moving around the crown. Copepods isolated from their hosts survived only ca. 2 days in both ambient and filtered seawater.

A total of 982 specimens of B. volutacornis were examined and a high incidence of infection registered, at $22.6 \%$, over the period of study. A chi-squared test showed a significant difference $\left(\chi^{2}=13.959, d f=1\right.$, $P<0.0005)$ when the sex ratio of copepods was examined, with males accounting for $64 \%$ of the population. A similar level of significance $\left(\chi^{2}=25.48, d f=1\right.$, $P<0.0005)$ was recorded when the sex of the hosts was examined, with $40 \%$ of the total polychaetes recorded as female. A number of polychaetes, however, could not be sexed due to the absence of gametes in the coelomic cavity. Prevalence varied between 3 and $90 \%$ during the study period and showed a seasonal pattern with a summer and late autumn/winter peak (Fig. 2). Intensity and mean intensity of $G$. clausii changed in a manner similar to prevalence. The intensity was $1.66( \pm 1.02)$ copepods per infected host in spring (April 1998) and peaked in autumn (October 1998) with $2.43( \pm 1.04)$ copepods per infected host. Mean intensity was $0.12( \pm 0.34)$ copepods per host in spring (February 1998) and peaked in autumn (October 1998) with $0.77( \pm 0.34)$ per host. Sample variance, at $S^{2}=0.91$, was much larger than the mean intensity $(\mathrm{MI}=0.39)$, yielding an overall dispersal index of 2.34 indicating a characteristically clumped pattern. Accordingly, the distribution of copepod numbers per host was modelled using a negative binomial relationship $\left(S^{2}=0.91\right.$, $8=0.39, k=0.314)$. A significant agreement is recorded between the observed frequencies and the expected negative binomial frequencies using a chi-squared test $\left(\chi^{2}=1.364, d f=7, P=0.987\right)$.

Polychaetes infected with a single copepod predominated, with a maximum number of ten copepods recorded from a single branchial crown. The smallest host observed had a branchial crown in the range 21-40 radioles (size group 1). The general trend in infection was increasing prevalence and mean intensity in hosts of increasing sizes, with a maximum in the size group 161180 radioles of $29.3 \%$ and 0.62 , respectively.

Recently settled copepodid stages first appeared during the summer (Fig. 3), with the smallest copepods and maximum number recorded during autumn (August to October), $563.2 \mu \mathrm{m}$ male and $652.0 \mu \mathrm{m}$ female. $G$. clausii reached adulthood in males at ca. $800 \mu \mathrm{m}$ in length and ultimately attained lengths of up to $1,875 \mu \mathrm{m}$. Females, at maturity, were recorded to be ca. $1,000 \mu \mathrm{m}$, with a maximum length of $3,250 \mu \mathrm{m}$ recorded for an ovigerous female.

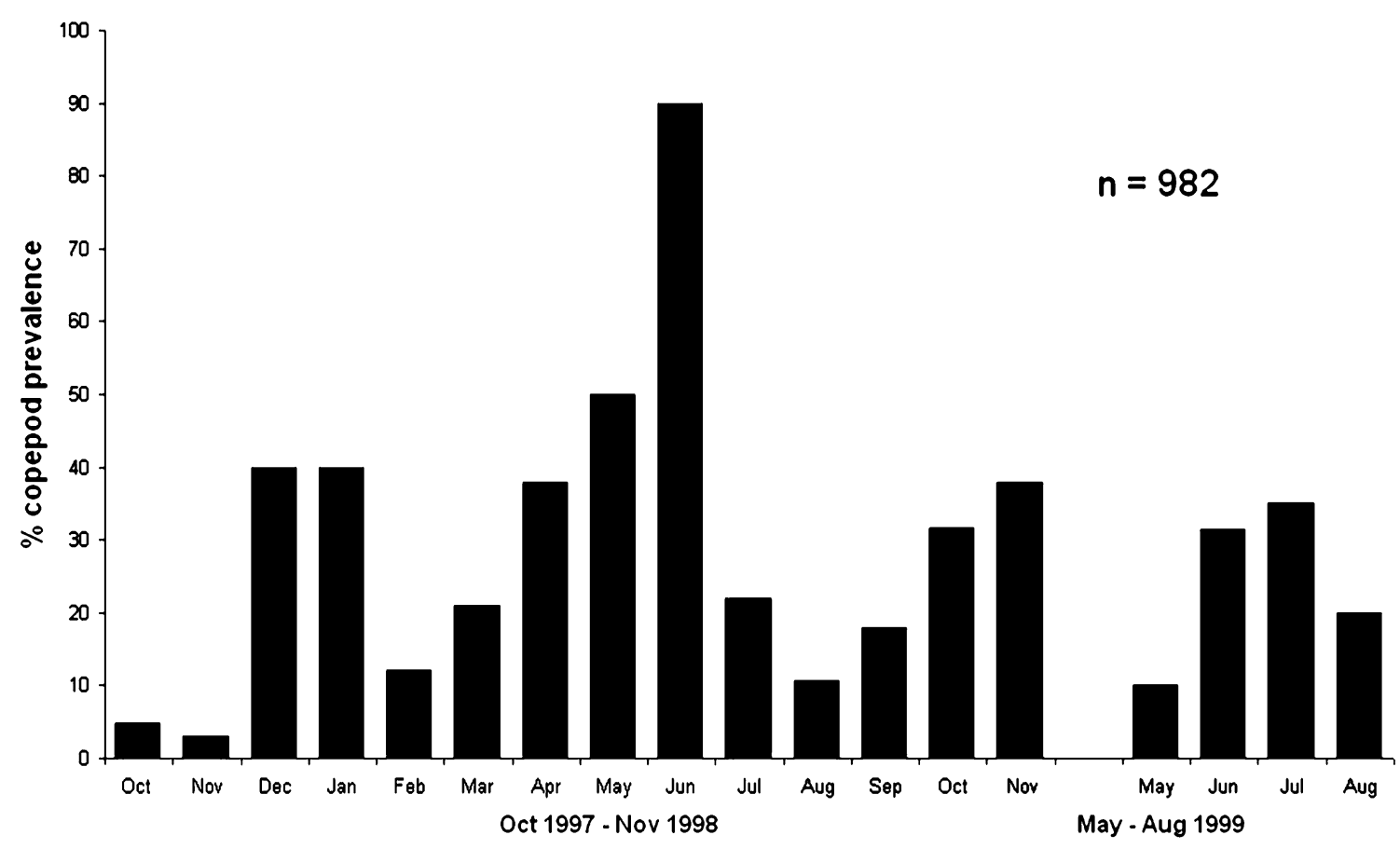

Fig. 2 Percentage prevalence of Gastrodelphys clausii recorded in each sample of Bispira volutacornis over the study period October 1997 to November 1998 and May to August 1999. High percentage prevalence recorded in June is a reflection of small sample size 

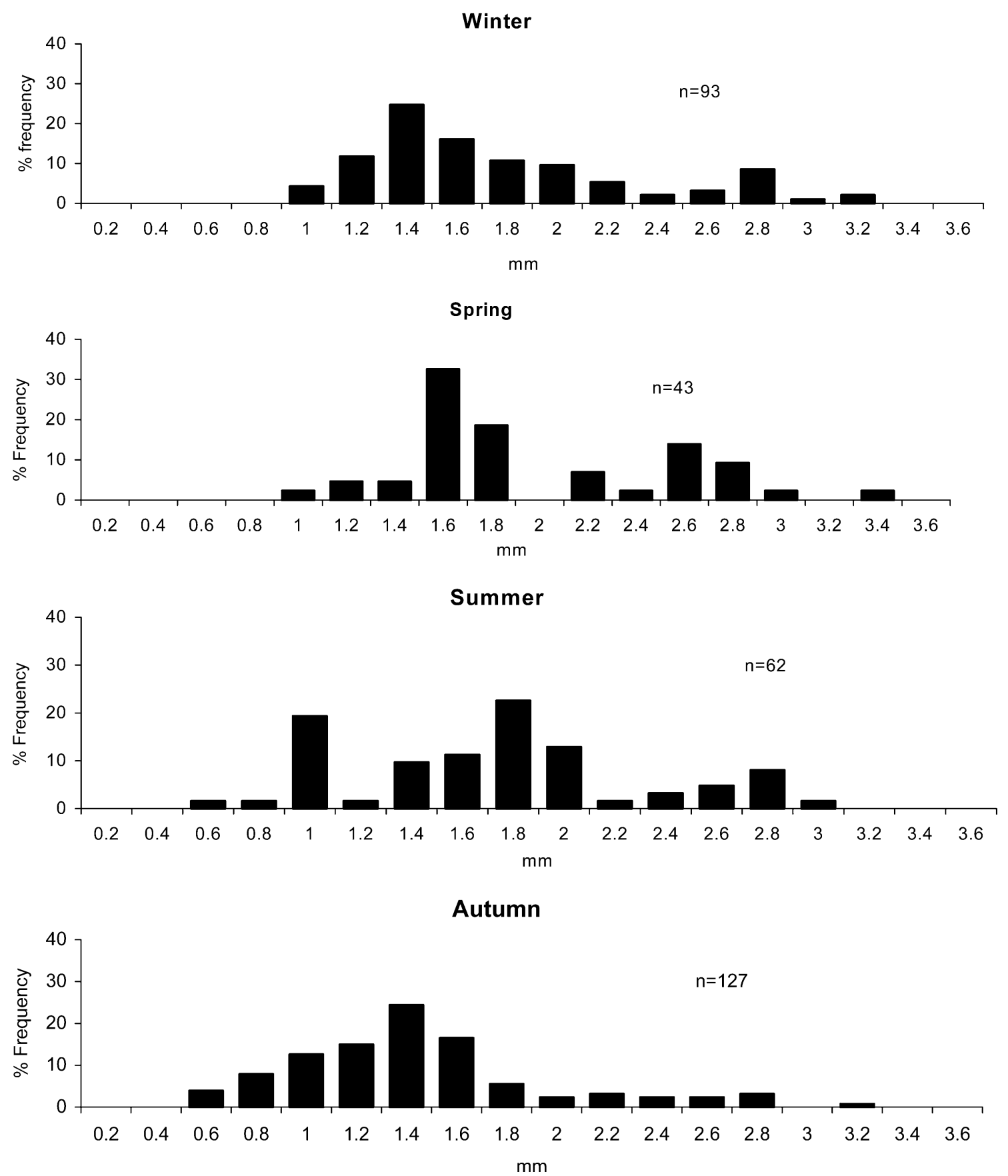

Fig. 3 Seasonal size frequency histograms for Gastrodelphys clausii. Winter (Nov 1997-Jan 1998, Jan 1999); Spring (Feb-April 1998); Summer (May-July 1998, 1999); autumn (Aug-Oct 1998)

A size frequency histogram for $G$. clausii is given in Fig. 4. Four cohorts were identified for the female copepod and three for the male, with a separation index $>2$. The first cohort in both contains the juvenile copepodid stages. In the female cohorts, a second group has been defined, which contains the 'first' adult females, with a mean of $1.26 \mathrm{~mm}$.

Copepods were found throughout the radioles of the branchial crowns of $B$. volutacornis with spirals greater than 20 radioles. Ovigerous females were found throughout the year except for November, with the greatest number registered during mid- to late-summer, with some having recently released nauplii, as evidenced by the presence of a posterior opening to the urosome. When resting, feeding and during rapid movement of the branchial crown, both antennae gripped the same pinnule in order to avoid dislodgement. Without exception, all copepods, adult and juvenile, aligned themselves parallel to the radiole attached to the base of the pinnules, with their heads pointing towards the radiole tips. 
Fig. 4 Copepod distribution for Gastrodelphys clausii attached to host Bispira volutacornis

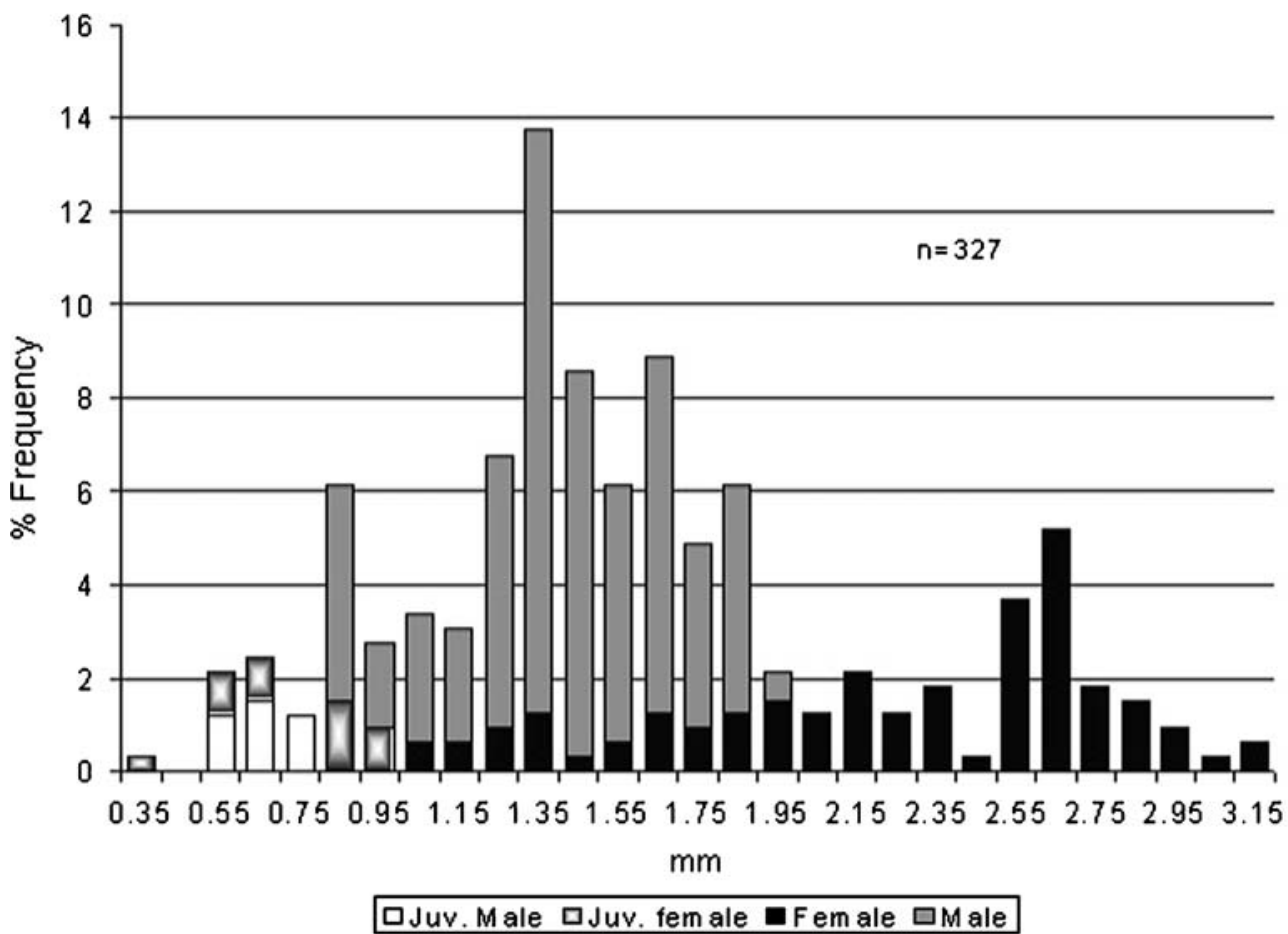

All copepods, male, female and juveniles, were mobile moving throughout the crown via pinnular attachment by the second antenna. Movement was displayed in a 'swinging' fashion between pinnules (Fig. 5). The male copepod appeared to be more agile than the female, moving quickly up and along radioles. Upon dislodgement of a copepod from its radiole, it sank helplessly to the bottom. Its movements on the bottom of the container involved a sweeping motion of the lower body in both a left-right lateral and dorso-frontal direction, during which the caudal rami of the male may reach as far forward as to touch the maxillipeds. The urosome of the female displayed similar flexibility. Simultaneous to the movement described, the second antenna of the copepod continuously reached forward and only when a purchase was established did body movement cease.

The greatest proportion, $39 \%$, of copepods was recorded from branchial crown size category 3 . Results of a Pearson chi-squared test showed no significant difference between male, female and juvenile copepods recorded on the different size categories of $B$. volutacornis $\left(\chi^{2}=6.027, d f=6, P=0.42\right)$. However, when the size of each copepod was taken into consideration within the branchial crown size categories, a statistically significant difference was recorded $\left(\chi^{2}=32.136, d f=12, P=0.01\right)$. Within an infected branchial crown, a positional pattern was observed (Fig. 6). Juvenile copepods were seen to attach to 'younger' radioles as the crown increased in size. Adult males and females particularly were observed to have a preference for the 'older' radioles, e.g. $68 \%$ of females attached to the 'older' radioles $1-20$ in all branchial crown size categories $\left(\chi^{2}=47.052, d f=16\right.$, $P<0.0005)$. Females attached low on the radiole,

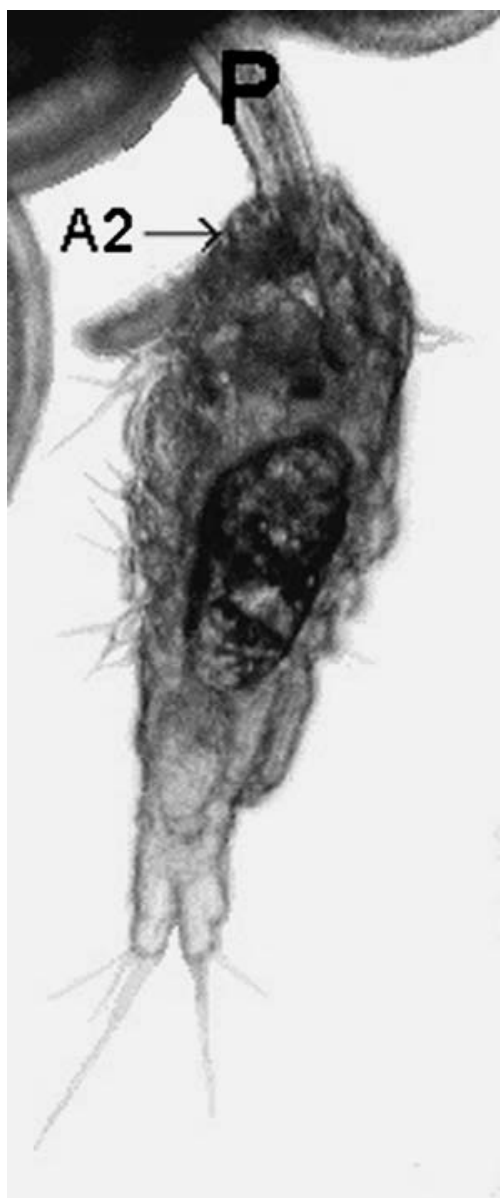

Fig. 5 A juvenile copepod attached to a pinnule on the branchial crown of its host Bispira volutacornis via its second antenna. $P$, Pinnule; $A 2$, Second antenna 

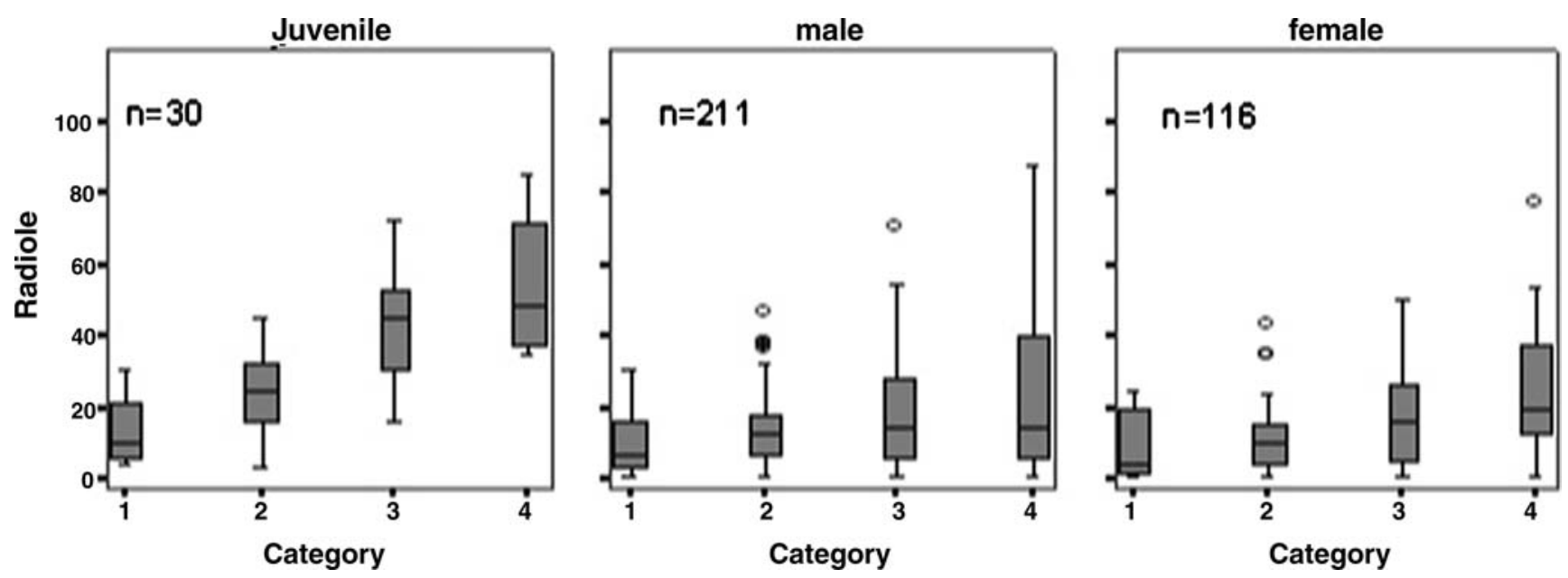

Fig. 6 Box plots showing the median and range of radioles to which juvenile, male and female copepods were recorded showing their positional pattern within the branchial crown groups $(1,21-40 ; 2,41-60 ; 3,61-80 ; 4,81-120)$. The lower the radiole number, the closer it is to the peristomium and the older it is in age

towards the basal web, whereas the males tended to be located higher up, about half way up on the radiole. Juvenile copepods were observed higher up on a radiole than either the adult female or male copepods.

\section{Discussion}

"When a comparatively active copepod is associated with the food-gathering organ of a filter-feeding invertebrate, it is perhaps natural to assume that it is living as a commensal" (Gotto 1960). Dudley (1964) believed that those species of gastrodelphyids that can change their position on the sabellid branchial crown are commensals. Gotto (1960) mentioned that Acaenomolgus protulae (Stock) was located on the frontal surface of the radiole, similar to $G$. clausii, and therefore was in a position to garner nutrients from the ciliary tracts of the radioles. Carton (1968) believed that the adult copepod Sabelliphilus sarsi (Claparede) fed on secretions from the sabellid Sabella spallanzani (Gmelin) rather than on host tissue. Similarly, the mouthparts of G. clausii do not appear to be adequately equipped to extract nutritive substances from the pinnules, although the antennae armature appears capable of damaging the epithelial tissue. While not definitively shown here, we are convinced of the parasitic nature of $G$. clausii, even though the actual deleterious effect on the polychaete appears to be minimal.

In copepod-invertebrate associations, comparatively few ill effects are discernible in most of the hosts involved (Gotto 1993), with the majority being overdispersed (Crofton 1971a) minimising any damaging effects that parasites may have on the host population. Østergaard and Emson (1997) showed that, irrespective of developmental stage, the parasitic copepod Parachordeumium amphiurae (Hérouard) is generally concentrated in the medium-sized individuals of the brittle star Amphipholis squamata (Delle Chiaje). Unlike $P$. amphiurae juveniles that are not host-size specific, the early stages of G. clausii appear to favour the intermediate radiole category 3 . With the exception of juvenile and adult specimens of $B$. volutacornis with rejuvenating branchial crowns of $<20$ radioles, all branchial crown sizes were found to be infected with G. clausii.

Seasonality in parasite infections, as seen here, is well known particularly in hosts at high latitudes where seasonal temperature changes are the greatest. Østergaard and Emson (1997) in South Devon, England, found seasonal changes, albeit with the numbers of the three stages of $P$. amphiurae somewhat sporadic throughout the year. The high prevalence and mean intensity of $G$. clausii in October are clearly due to the culmination of a major release of infective stages, which first appear in August and continue until October, suggesting that recruitment is seasonal. It was found that the release of the infective stages is generally and broadly synchronised to that of the host's reproductive cycle (Nash and Keegan 2003). The high prevalence of $90 \%$ recorded in June, unlike that in October, is not a reflection of juvenile copepods settling, as all copepods found attached were adults. The combination of a relatively small sample number collected, ten hosts, and the nature of the copepod being overdispersed may be the attributing factors to the peak recorded here in June and the apparent decline afterwards.

In most gastrodelphyid species, the mature females are associated with particular sabellids at the species level. However, the copepodids, adult males and immature females of $S$. illgi have been recorded to move between polychaetes of different genera and species which occur in the same area (Gotto 1979). The presence of a number of different cohorts, which included both copepodid and adult stages, and with the first copepodid stage thought to be the infective stage (Dudley 1964), seems to rule out the likelihood of an intermediate host 
or a second primary host; therefore it is suggested here that $G$. clausii is specific to B. volutacornis.

Gotto (1960), writing on the orientation and feeding of the copepod Sabelliphilus elongatus M. Sars on Sabella pavonina Savigny, mentions that the fringing pinnules are grasped very occasionally by adults but more frequently by copepodid stages. He also illustrated how the juveniles are not restricted to this region (i.e. fringing pinnules) but can be found amongst the adults on the abfrontal surfaces of the inner radioles. Gotto (1960) discovered that a remarkably high proportion of the population of $S$. elongatus may be concentrated on relatively few overlapping radioles. In $B$. volutacornis, juveniles of $G$. clausii are located higher up on the radioles and on 'younger' radioles than both adult males and females. We believe that the majority of G. clausii juveniles, found in the inner spirals of the branchial crown, are channelled here, similar to $S$. elongatus, through 'a local current of fractionally greater strength'. Unlike $S$. elongatus, the younger copepodid stages of $G$. clausii do not appear to be restricted to this latter area. With further development, the copepodite moves in the direction of the 'older' radioles where both adult female and male specimens of $G$. clausii are found to attach low on these radioles, towards the basal web in the former case. The size of the internal diameter of the hook-like claws of the second antenna of $G$. clausii by which they attach may also be influential in their location. Those pinnules located both higher up and on younger radioles are of slightly smaller diameter than the 'older' lower pinnules. Further study is required to corroborate these suggestions as to the dominant factors involved in the positional pattern observed in G. clausii.

The orientation of G. clausii, with its head towards the radiole tip, is the opposite of that seen by Gotto (1960) for S. elongatus on S. pavonina. Gotto (1960) suggests that the latter may be advantageous with regard to movement and attachment. Provided it is undisturbed, S. elongatus remains nearly motionless for long periods. The males of $G$. clausii are extremely active, moving up and down the radioles via the pinnules and between adjacent radioles. Although both females and juveniles do not appear as effectively mobile as the males, they too are seen to be less than static. Although dislodgement during withdrawal of $B$. volutacornis is also a possibility, due to the spiral nature of the crown and the fact that $G$. clausii is located on the frontal surface of the radioles, the chances of reattachment are considerably higher, than with S. elongatus, once dis- placed. Species of gastrodelphyids do seem to fall into two groups with respect to their habits on their particular hosts and to adaptive structural modifications associated with these habits (Dudley 1964). G. fernaldi Dudley and G. myxicolae list are similar to G. clausii in attaching by means of their antennae and rostra, whereas $S$. gracilis $M$. Sars and $S$. illgi are embedded in the tissue of the radiolar base, or oral surface of the polychaete, and are essentially sessile (Dudley 1964).

Acknowledgements Sincere thanks to the late Professor B. F. Keegan for his continuous encouragement and guidance throughout the course of my studies. Thanks also to Professor Julie Fives for extending the facilities of the Zoological Department at the Martin Ryan Institute, National University of Ireland, Galway. The technical assistance of Mr. Albert Lawless, Mr. John Galvin and Mr. Nicolas Donohue is also very much appreciated.

\section{References}

Bhattacharya CG (1967) A simple method of resolution into Gaussian components. Biometrics 23:115-135

Carton Y (1968) Spécificité parasitaire de Sabelliphilus sarsi, parasite de Spirographis spallanzani. Archiéves de zoologie experimentale et generale 109(1):123-144

Crofton HD (1971) A quantitative approach to parasitism. Parasitology 63:179-193

De St Joseph A (1894) Les Annélides Polychètes des côtes de Dinard. Troisième partie Ann Sci Nat Zool Paris 17(7):286-293

Dudley PL (1964) Some Gastrodelphyid copepods from the Pacific Coast of North America. Am Mus Novit 2194:1-51

Gayanilo FC, Sparre P, Pauly D (1995) The FAO-ICLARM Stock Assessment Tools (FiSAT) User's Guide. FAO, Computerized Information Series (Fisheries), Rome pp 126

Gotto RV (1960) Observations on the orientation and feeding of the copepod Sabelliphilus elongatus M. Sars on its fan-worm host. Proc R Zoo Soc 133:619-627

Gotto RV (1979) The association of Copepods with marine invertebrates. Adv Mar Biol 16:1-109

Gotto V (1993) Commensal and parasitic copepods associated with marine invertebrates (and whales). In: Kermack DM et al (eds) Synopses of the British Fauna, vol 46. Universal Book Service/ Backhuys, Oegstgeest, pp 144-145

Graeffe E (1883) Gastrodelphis clausii nov gen et spec Boll Soc Adriat Sci Naut (Trieste) 8(1):206-214 (+Figs 1-6)

Huys R, Boxshall GA (1991) Copepod evolution. The Ray Society, London

List JH (1890) Das genus Gastrodelphys. Zeitschr Wiss Zool 49:71-146

Nash R, Keegan BF (2003) The reproductive cycle of Bispira volutacornis (Montagu) (Polychaeta, Sabellidae) on the West Coast of Ireland. Mar Biol 143(5):919-925

Østergaard P, Emson R (1997) Interactions between the life histories of a parasitic copepod, Parachordeumium amphiurae, and its brittle-star host, Amphipholis squamata. J Crust Biol 17(4):621-631 